\title{
HISTÓRIA DA FILOSOFIA, FORMAÇÃO E COMPROMISSO ${ }^{1}$
}

Franklin Leopoldo e SILVA ${ }^{2}$

n RESUMO: A questão que se tenta construir neste texto é a da convergência entre filosofia, história da filosofia e formação. Tal pergunta se desdobra primeiramente na elucidação das relações entre história e historicidade da filosofia, que remonta à constatação óbvia, mas nem sempre lembrada, de que o fundamento da história da filosofia é o caráter histórico da própria filosofia. A idéia de formação está presente em toda filosofia, já que, antes de ser sistema ou concepção cristalizada da realidade, cada filosofia é sempre um exercício de síntese das possibilidades e das circunstâncias da vida humana, inclusive sob o aspecto do trabalho da reflexão. Nesse sentido, o texto remete a algumas idéias de Bergson acerca de formação e processo, e à noção sartriana de práxis como formação e superação contínua dos momentos estruturais do curso da história. Assim compreendida, a relação entre história da filosofia e filosofia contém inevitavelmente o compromisso com a atualidade, isto é, com a formação atual do pensamento.

n PALAVRAS-CHAVE: História; processo de formação; tempo histórico; reflexão; negação.

Todos os que trabalhamos com o ensino da filosofia, em qualquer grau da formação, sabemos que não é fácil justificar a nossa tarefa e afirmar, no quadro de nossa degenerescente contemporaneidade, os fatores de

\footnotetext{
1 Texto apresentado na XXV Jornada de Filosofia e Teoria das Ciências Humanas da UNESP História e historiografia da filosofia, Marília, outubro de 2001

2 Professor do Departamento de Filosofia da FFLCH da USP.
} 
relevância que constituem o sentido da filosofia. E qualquer exame superficial das pressões que delimitam na atualidade as exigências de inserção social nos revelará que a causa dessa dificuldade está precisamente no desaparecimento do ideal de formação em todos os níveis de ensino, mas em particular, do ponto de vista que nos interessa, na universidade. Já o próprio fato de nos referirmos à formação como um ideal significa que ela desapareceu completamente do horizonte educacional, a ponto de não constituir já nem mesmo uma idéia reguladora. E como a educação é uma prática concreta, a filosofia tende a assumir, num contexto em que predomina a urgência do adestramento instrumental, uma posição abstrata. Sofremos então, nós os professores de filosofia, da síndrome do deslocamento, porque não conseguimos fixar, no quadro social e institucional, o lugar de onde falamos.

Por outro lado, é visível que esse mesmo ambiente sócio-histórico que recusa a filosofia experimenta a sua necessidade, sem no entanto compartilhar a compreensão das razões dessa necessidade. Somos solicitados, a partir de nossa marginalidade, por diferentes setores da universidade e da sociedade, seja para colaborar na elucidação de questões epistemológicas e metodológicas, seja para emprestar nossa competência profissional a assuntos ligados à ética da pesquisa e das profissões (como se a ética fosse uma questão de competência), seja para esclarecer os fundamentos e os valores da conduta social e política, seja para refletir acerca do fazer artístico. O que essa diversidade de situações revela, a partir dessa necessidade difusa e por vezes confusamente compreendida, é a experiência de uma falta que se tornou constitutiva da racionalidade técnica que impregna tão fortemente a nossa cultura. Essa falta pode ser vivida como a superação da reflexão, caso em que a instrumentalidade racional se consolida e se vê como auto-suficiente; ou como o recalque de uma possibilidade mais profunda e mais totalizante de inserção das teorias e das práticas num horizonte mais amplo em que ressaltaria o sentido que possuem.

Mas essa situação não constitui uma justificação positiva da filosofia: indica antes uma presença residual derivada talvez do fato de que o processo de desaparecimento do ideal formativo ainda não engendrou o total e definitivo esquecimento da diferença entre o fato e o sentido, ou que a factualidade técnico-instrumental ainda não absorveu no seu imediatismo bruto todos os resquícios de significação transcendente. Mas o processo está em marcha, e pode-se supor até mesmo que a tecnização da própria filosofia será provavelmente a sua última etapa.

Isso torna natural que a justificação da filosofia seja buscada na sua própria história. O que temos a apresentar como argumento contra a su- 
peração da filosofia é o seu próprio passado, justificativa de certo modo frágil, já que não leva em conta que um dos motivos principais do enaltecimento da atualidade é o progresso: a ausência de um lugar para a filosofia no presente decorreria precisamente de que o progresso histórico teria naturalmente superado a sua necessidade. Seria preciso mostrar que a continuidade histórica da filosofia não é fruto da inércia, que não é apenas o peso morto do passado que incide sobre o presente, como um efeito de retardamento, mas que a filosofia cumpre sua história por sucessivas reatualizações de si mesma. Somente nesse caso seria possível escapar da acusação de que a filosofia vive do prolongamento de sua morte. É certo, então, que a justificação da filosofia está na sua história, mas desde que vejamos nessa história não o deperecimento de uma determinação cultural, mas a reiteração constante de que a própria cultura inclui no seu processo constitutivo o movimento de transcendência do fato ao sentido, e que é nesse movimento que a reflexão confere às produções humanas o elo histórico que as vincula entre si e com a totalidade para a qual apontam. Dito de outra maneira, a importância da história da filosofia na justificação da filosofia deriva de que a filosofia é histórica, não apenas no sentido de um produto histórico configurado nas teorias que se sucedem, mas principalmente no sentido de que a filosofia é a elaboração histórica da presença do espírito objetivo a si mesmo. Isso significa que a historicidade humana só existe pelo testemunho da consciência reflexiva.

Aproximamo-nos assim da sua especificidade. A filosofia, pelo menos de um ponto de vista histórico, é a reflexão autônoma acerca das vinculações entre as teorias e as práticas humanas, e sua finalidade é constituir o quadro complexo da historicidade, por via dos sentidos que se constroem nessas diferentes relações. Disso decorre que a filosofia é, indissociavelmente, teórica e prática, e cabe à história da filosofia desvendar os liames, por vezes contraditórios, que constituem essa indissociabilidade. "Para dizer com outras palavras, a questão do sentido é inseparavelmente teórica e prática. Ela encontra em dois mil anos de pensamento filosófico a história de sua elaboração assim como os instrumentos de sua configuração, e na vontade de construir o futuro humano sua perpétua atualidade" (Garo, 1990, p.42). A autonomia necessária à elaboração histórica da forma como cada filosofia procurou constituir-se como sabedoria, isto é, como harmonização de teoria e prática, não deriva apenas do teor crítico da abordagem historiográfica, no que não caberia insistir, mas no empenho de compreensão concreta dessas produções de totalidade. A autonomia do historiador não o desvincula das circunstâncias, injunções e conjunturas da produção efetiva do saber filosófico, porque 
não é possível compreender de forma neutra aquilo que se fez a partir de encarnações históricas concretas e comprometidas; a autonomia o livra da submissão à atualidade que deseja compreender. Mas essa independência é solidária de um compromisso: o de desvendar uma atualidade histórica não apenas no jogo de idéias ali produzido, mas na efetividade da gênese crítica do processo de reflexão. Em suma, uma história que se recusa a ser crítica perde o teor crítico intrínseco à reflexão que pretende reconstituir. É nesse sentido que a história da filosofia não pode se constituir como a contemplação de monumentos construídos ao longo da história do pensamento. Como a filosofia é histórica e a história é devir, o próprio sentido das produções humanas é inseparável das condições em que a teoria transfigura a prática e atinge reflexivamente o seu significado. Não devemos entender por isso que as teorias filosóficas sejam apenas figurações das práticas humanas. Como toda prática é por si mesma figuração do pensamento, de desejos e de aspirações, a única maneira de compreender o sentido delas e das teorias que as exprimem é a vinculação reflexiva entre vida e pensamento, na tentativa de formular uma síntese entre a figuratividade prática do pensamento e a figuratividade teórica da práxis. Somente assim as filosofias do passado deixam de ser monumentos cristalizados com os quais mantemos uma relação quase fúnebre, para recuperarem um pouco do caráter de ações vivas de compreensão e elucidação da atualidade. É essa compenetração teórico-prática num mesmo sentido da ordem humana que nos mostra a maneira como, em cada época, em cada caso, a reflexão forma uma compreensão ao menos tentativamente totalizante.

Apreender a filosofia - as filosofias - a partir do enraizamento histórico não é vê-la(s) como mero(s) reflexo(s) da condição histórica na qual foi(ram) produzida(s), mas vê-la(s) como elaboração privilegiada do sentido que vincula essas condições às diversas formas como os sujeitos históricos as vivem. É precisamente nessa elaboração que se constata em ato a liberdade da reflexão. Ninguém é livre para anular certa camada da factualidade: a época em que vive, a classe social a que pertence, a configuração cultural a partir da qual irá pensar a si mesmo e ao mundo. A liberdade está em transcender essa factualidade compreendendo-a e, se possível, transformando-a. Apreender o enraizamento histórico das filosofias é apreender o nosso próprio enraizamento e, assim, reatualizar as questões, reatualizar a filosofia que, então, deixa de se alimentar de sua própria inatualidade, deixa de viver melancolicamente do adiamento de sua morte. E sobretudo a apreensão do enraizamento nos ensina que este não pode nunca ser confundido com a submissão pura e simples à atuali- 
dade. Já Bergson, que não poderia ser suspeito de historicismo, afirmava que o primeiro ato filosófico é a negação. O filósofo, em face da cultura de sua época, das concepções consolidadas, primeiramente nega, mesmo que, num primeiro momento, saiba apenas de forma muito confusa em nome de que está negando (Bergson, 1989, p.175 ss.). E seu pensamento se construirá, tanto a partir do núcleo intuitivo quanto da explicitação discursiva, a partir dessa negação. Esse ato de negar não significa que o filósofo se destaca de forma absoluta das condições em que vive e pensa. Pelo contrário, é do interior mesmo dessas condições às quais não se poderia furtar que ele as nega como primeiro passo para elaborar uma nova compreensão desse mesmo contexto e do que ele significa. Esse advento histórico da filosofia - de uma filosofia - pode até ser a reiteração intuitiva deste, mas será ao mesmo tempo novo e se produzirá contra as elaborações vigentes. A primeira das intuições filosóficas é então esta: que é preciso pensar de novo e por si mesmo, na atualidade, a atualidade, mesmo que essa nova elaboração seja inseparável do aporte da tradição, criticamente reconstituída.

Eis pois uma primeira conclusão. Se o filósofo transcende a sua época e a sua cultura para melhor pensá-las, para formar uma compreensão autônoma daquilo mesmo que o pressiona por todos os lados, essa transcendência é uma liberdade comprometida. Se vamos então fazer a história desse movimento pelo qual a filosofia se constitui e se reconstitui, é primeiramente a compreensão dessa fidelidade infiel que nos deve guiar, para que a história seja antes de tudo a compreensão desse engajamento originário e concreto, e não o desfile de idéias como comemoração do universal abstrato. A compreensão da transcendência como negação vincula a elaboração do sentido a um profundo enraizamento de cada filosofia na sua atualidade. Na medida em que filosofar se conjuga sempre no presente, é preciso que a reconstituição de uma filosofia do passado seja ao mesmo tempo uma interrogação acerca de como o filósofo interrogou o seu presente. Isso nada mais significa do que manter fidelidade ao caráter interrogante da filosofia, compreendendo que as respostas filosóficas têm como maior virtude não a afirmação definitiva, mas o se constituírem em novas interrogações. A compreensão da relação viva que cada filósofo manteve com a sua época nos ensina a interrogar a nossa (Merleau-Ponty, 1962).

Esse modo de interrogação só pode ser uma "apropriação ativa do pensamento e de sua história" (Garo, 1990, p.45). Como se pode apropriar ativamente de algo que se cristalizou em passado? Muitas vezes tendemos a ver na história da filosofia uma série de fatos do espírito. 
Assim como a história dos acontecimentos privilegia os fatos eventuais, a história do pensamento estaria atenta aos fatos do pensamento. Poderíamos narrá-los e encadeá-los, mas não poderíamos, certamente, coincidir com a sua efetuação, a menos que pensássemos, como Bergson, que existiria uma intuição filosófica intemporal por trás de cada sistema, da qual nos poderíamos aproximar pelo viés da simpatia. Mas se consideramos que essa intuição, supondo que exista, é paradoxalmente construída pelo esforço reflexivo que todo filósofo sente como insuficiente para expressá-la, deveríamos vê-la então não tanto como uma inspiração atemporal, mas como o trabalho sempre incompleto da filosofia para totalizar a apreensão de sua época. Assim, a negação que está na origem de todo pensamento filosófico significa que a reflexão se defronta com possibilidades, e que a escolha entre elas se fará por meio da liberdade de pensamento concretamente exercida. Essa liberdade, contudo, não coloca o filósofo acima de seu tempo, mas diante das possibilidades que são historicamente oferecidas. $\mathrm{O}$ exercício concreto da liberdade de pensar não deve ser visto como uma expansão da vontade no vácuo, mas como um confronto efetivo entre o pensamento e as determinações históricas que o limitam e definem o seu campo de efetuação. A liberdade é o esforço do pensamento para liberar-se redefinindo seu alcance, isto é, seus limites. É de acordo com essa relação dialética entre a positividade e a negatividade que o pensamento elege suas possibilidades e as realiza. As determinações históricas não podem ser visadas de forma separada do modo como os sujeitos históricos as vivem; e estes não podem ser compreendidos fora dessa relação de apropriação ativa daquilo mesmo que os determina.

Sendo assim, a história da filosofia não pode ser vista como sucessão linear e ordenada de figuras da racionalidade que naturalmente se alinham ao longo de um processo entendido como um percurso pré-estabelecido e teleologicamente constituído. Essa visão retrospectiva seria mais lógica do que histórica. Se há uma apropriação ativa da história em cada momento histórico, o pensamento se constrói a partir da significação que o passado assume para um dado presente, porque o passado é sempre passado para um certo presente que o visa como tal e lhe atribui significação. Se atentarmos para essa constituição concreta da temporalidade, isto é, uma temporalidade em que os sujeitos são testemunhas de seu presente e de seu passado, então os fatos que porventura venham a se consolidar seriam antes de tudo significações e valores produzidos por uma certa visão do presente e do passado - e também por uma certa expectativa de futuro. A filosofia se transforma no seu desenvolvimento 
temporal porque os filósofos que sucedem a outros filósofos não consideram o que foi pensado pelos seus antecessores como fatos mas sim como construções significativas e valorativas legadas pelo passado e, assim, susceptíveis de serem retomadas a partir de novas possibilidades em termos de significações e valores. É nesse sentido que as escolhas efetuadas pela liberdade da reflexão, nas condições a que já nos referimos, obrigam-nos a considerar a sucessão das teorias filosóficas a partir de uma temporalidade concreta, e não apenas de um encadeamento formal e abstrato de idéias. Uma recusa radical do positivismo histórico supõe, pois, uma visão da gênese teórica das concepções filosóficas a partir da negação e da escolha de possibilidades dentro de um campo de liberdade reflexiva aberto concretamente pela situação histórica vivida. Fazer história da filosofia a partir desses parâmetros de orientação significa tentar reconstituir a formação de significações e valores e não o engendramento factual de idéias. Significa supor também que só há idéia filosófica quando a factualidade foi de alguma maneira superada. Por isso não poderíamos voltar a considerar como fato aquilo que somente surge ao serem transcendidos os fatos. Não se pode, naturalmente, nutrir a pretensão de reconstituir um processo interrogativo na originalidade concreta de cada caso ou de cada situação histórica particularmente vivida. Mas é importante considerar as tensões presentes na formação das filosofias entendidas como elaborações teóricas dentro das possibilidades da consciência histórica. A sedimentação conceitual é resultado de um movimento crítico que só pode ser apreendido por um outro movimento crítico.

Essa preocupação com a formação é que impede que a história da filosofia seja considerada um patrimônio histórico da humanidade aberto à visitação. Trata-se de habitar, mais do que de visitar (Garo, 1990, p.46). A história monumental não condiz com o trabalho do historiador da filosofia. Tudo o que mencionamos até aqui leva a uma opção pela história crítica, para utilizarmos a distinção de Nietzsche. A história crítica permite a apropriação ativa porque não confere à herança histórica a positividade bruta do fato. Ao considerarmos que a história se faz por eleição de possibilidades, relativizamos a sedimentação que resulta das opções doutrinais, isto é, repomos algo que nos é apresentado como feito na contingência de sua produção. Essa relativização não significa igualar todas as possibilidades e assim remeter tudo o que foi feito a uma irremediável gratuidade. Pelo contrário, toda filosofia traz naturalmente ao seu presente algo de afirmação dogmática, o reverso da negação exercida em relação às outras filosofias. A relatividade somente aparece quando a doutrina é reposta na temporalidade de sua elaboração como formação 
de idéias. É certo que daí resulta um monumento; mas também é certo que este só nos transmite verdadeiramente a sua significação quando convivemos criticamente com o processo de produção que podemos acerca dele reconstituir, apropriando-nos dele, habitando-o e não apenas contemplando-o como elemento da paisagem histórica.

Isso nos leva a considerar a estrutura e o processo, e que tipo de relação podemos aí estabelecer. Sabemos que a polêmica gerada algumas décadas atrás levou à consideração de que estrutura e processo seriam irremediavelmente opostos. Vejamos se há algum outro caminho a tomar a partir do que já constatamos até aqui. Na Evolução criadora, Bergson considera, como se sabe, as formas naturais como resultados sempre provisórios e parciais de um processo de evolução concebido como a trajetória do élan vital. As formas que constituem a nossa realidade natural seriam produtos dessa trajetória, não no sentido de uma finalização ou da realização do processo, mas como traços que o élan vai deixando em seu caminho. Observe-se que tais traços existem porque o élan possui uma espécie de intenção formadora no seu próprio percurso, mas a realização desse "propósito" está posta no infinito. Nesse sentido as formas existem a partir de um processo de formação: o caráter aparentemente óbvio dessa afirmação se complica um pouco quando perguntamos o que se deve considerar como elemento primário: se a forma ou a formação. Na perspectiva bergsoniana não há qualquer dúvida de que o processo de formação é anterior às formas por ele depositadas ao longo do devir. Ainda assim, não se pode ignorar que as formas são expressões do processo. Na verdade, em que pese a anterioridade da formação, a compreensão do processo depende em grande parte das formas que pontuam a trajetória evolutiva do élan. É a diversidade e a relação das formas entre si que apontam para o caráter primário do processo; tanto é assim que temos de inverter o modo habitual do raciocínio para passarmos da estabilidade das formas ao movimento que as engendra. No que concerne aos planos moral, social e religioso, considera Bergson também que as formas definidas de obrigação moral, de organização social e de religião positiva ocorrem a partir de um movimento espiritual de superação histórica do constituído, cuja continuidade não é aparente porque tendemos a privilegiar a estabilidade adquirida e não o movimento de que resulta. Isso significa que, em ambos os casos, temos as formas como estrutura expressiva e o processo como movimento de constituição progressiva dessas organizações.

Se transferimos essa visão da relação entre o sincrônico e o diacrônico para a história, encontramos algo análogo: o historicamente constituído e o 
processo histórico de constituição. Como só podemos reconstituir o processo a partir dos seus resultados, uma lógica retrospectiva atua poderosamente no sentido de interpretarmos o processo em função de seus resultados, o que de forma alguma reproduz a realidade no seu movimento de fazer-se tal ou qual determinação. Isso significa que a realidade da estrutura é residual: ela apenas deveria levar-nos a entender o processo fundamentalmente real de formação, de acordo com a hierarquia que Bergson estabelece entre a duração e os objetos na duração. $\mathrm{O}$ que é notável nessa relação entre a duração histórica e a sedimentação das realidades humanas instituídas é que o movimento de superação é realizado excepcionalmente por individualidades privilegiadas (moralista, místico) que inventam novas direções de sociabilidade, de religiosidade, de moralidade. A humanidade progride quando transforma essa criação em instituição, ou seja, quando congela o ato instaurador e o traduz em outras estruturas históricas.

Para Sartre (1960), o instituído é sempre também o resultado de um processo. Mas nesse caso a estrutura é fruto de uma práxis constituinte pela qual o social se produz e se reproduz em sistema. A estrutura fixa momentos de uma práxis em que a sociedade se reconhece como sistema que a identifica, isto é, que ela pode tender a reproduzir e perpetuar. Portanto toda expressão sistemática da práxis é estrutural (Grisoni, 1982). Mas o sistema é a expressão de um processo de produção do pensamento que, sendo histórico, envolve o aspecto social de toda produção. A compreensão da expressão sistemática estrutural envolve necessariamente a sua produção, ou o processo dialético de formação. A diferença, fundamental, em relação a Bergson, é que a produção e a superação das estruturas ocorrem pelo processo coletivo da práxis humana e não pela intervenção de indivíduos excepcionalmente dotados para a criação do novo. É preciso considerar, portanto, a expressão sincrônica das estruturas; e o processo diacrônico - dialético - de produção prática das estruturas. Podemos dizer que há, em Sartre, também uma hierarquia que considera o processo como elemento primário. Mas o que caracteriza esse processo, e a produção de estruturas, é a historicidade. Em Bergson, o aparecimento do ato criador e transformador interrompe de alguma maneira a estabilidade histórica. Em Sartre, é a própria práxis que vai gestando a sua própria superação, pela relação dialética que se estabelece entre seus momentos. A negação interna substitui aqui a interrupção voluntarista da estabilidade estruturalmente organizada.

Essa diferença se reflete na concepção da relação entre processo e estrutura na história da filosofia. Em Bergson a negação surge como 
momento preliminar da intuição, que não estaria ligada à praxis histórica negada pelo filósofo. A filosofia surge apesar da história, embora só possa surgir na história. Em Sartre a filosofia surge como expressão de um processo histórico pelo qual a práxis nega-se internamente e institui outras formas de se autocompreender. A filosofia somente surge na história e como expressão histórica. E isso primeiramente porque o processo de transformação do pensamento é caracterizado pela historicidade, e em segundo lugar - mas talvez sobretudo - porque a realidade humana que a filosofia tenta compreender é essencialmente historicidade. Nesse sentido a articulação temporal concreta a partir da qual se dá o pensamento é marcada pela simbiose entre a abertura dos possíveis e a limitada clareza que todo ser humano possui acerca de suas opções de interpretar o mundo e de nele agir.

Se a filosofia responde a essa dialética interna da práxis, ela é inseparável de um compromisso com a realidade. Não estaria esse compromisso presente de várias formas desde a origem da filosofia? Seria talvez redundante mostrar essa atuação comprometida do filósofo em Sócrates e Platão; mas a própria filosofia pré-socrática, que se costuma entender como tão voltada para a compreensão do cosmos, não poderíamos também encontrar nela o compromisso de compreensão do universo como meio de situar nele o homem? (Marcuse, 1975). Talvez a relação que a filosofia manteve com a realidade se tenha caracterizado pela ambivalência: por vezes o filósofo desvaloriza o mundo real até o limite de sua negação; por vezes somente vê em todas as tentativas humanas de apreender o mundo e seu sentido apenas equívocos e fracassos. Mas essa desqualificação provém de que ele leva até o extremo limite o valor do conhecimento verdadeiro da realidade; entende que seja necessário um longo desvio do imediatamente dado como real para que o real seja apreendido em sua verdade. Entende que essa é a primeira e mais longa tarefa, necessária para que todas as demais possam ser adequadamente desempenhadas. Aí residiu desde sempre a ambigüidade presente na relação entre o filósofo e a cidade, ou a comunidade humana. Por isso ele por vezes começa por negá-la, mas é sempre porque pretende reencontrá-la de forma mais autêntica. Pois o conhecimento da realidade é necessário para a sua transformação. A célebre tese de Marx sobre Feurbach não opõe interpretação e transformação da realidade, nem exclui da transformação o conhecimento. Visa justamente negar que sejam termos mutuamente excludentes, deslegitimando a opção exclusiva pela interpretação.

A história da filosofia não pode separar as idéias do compromisso motivador de sua formação, principalmente se a própria história da filo- 
sofia for considerada um componente formador. É por isso que a consciência filosófica se forma através da compreensão da formação da filosofia. Isso não significa apenas que o processo histórico é relevante; significa sobretudo que é a relevância da realidade que exige a sua compreensão como processo. É nesse sentido que a filosofia transcende a realidade para melhor fazer-se imanente a ela; é nesse sentido que o filósofo se destaca do mundo para elaborar a compreensão interna do mundo. Quando essa compreensão era definida como, antes de mais nada, a síntese transcendente do real - a totalidade na mente de Deus - a elaboração compreensiva tendia para a sua completude na positividade absoluta da causa de todas as coisas. A partir do momento em que essa compreensão passou a visar a síntese entre a subjetividade e a história, ela tornou-se a elucidação do processo de totalização pelo qual a realidade humana apreende o seu sentido ao mesmo tempo que o elabora. A compreensão radical da finitude não autoriza a pretensão da totalidade, mas exige a compreensão do processo de totalização, constitutivamente inacabado. Nenhum momento da temporalidade ocorre isoladamente; do mesmo modo não há compreensão de qualquer desses momentos que possa se dar isoladamente. As estruturas compreensivas historicamente elaboradas são produtos da formação constitutiva das teorias, se as entendermos sempre como produções históricas de saber. Essas produções são expressões da liberdade de pensamento pela qual a filosofia exerce sua função crítica e negativa. Como a liberdade humana não é atemporal, toda elaboração filosófica é marcada por uma espécie de síntese paradoxal entre autonomia e limitação: liberdade do pensamento e configuração histórica da práxis sobre a qual e a partir da qual o pensamento se exerce. A história da filosofia só será fiel ao seu objeto se puder reconstituir essa temporalidade complexa da reflexão, a partir da qual se constitui o compromisso da expressão filosófica na singularidade de cada tentativa de apreensão sintética do sentido da realidade.

SILVA, F. L. History of philosophy, formation and commitment. Trans/Form/Ação (São Paulo), v.25, p.7-18, 2002. 
n ABSTRACT: The text intends to examine the question about the relationship between history of philosophy, philosophy and formation as a liberation of conscience. The starting point is an obvious idea, thought not always remembered: history of philosophy founds its legitimation on philosophy as historical cultural fact. The idea of formation is implicated in every system, which, before being a specific conception of reality, is a synthesis of real conditions that have influenced all aspects of human life, includingly reflexive work. Some of Bergson's and Sartre's ideas about process, form and praxis can help us to elucidate the engagement in the present included in the relationship between philosophy and history of philosophy.

n KEYWORDS: History; formation process; historical time; reflexion; negation

\section{Referências bibliográficas}

BERGSON, H. A intuição filosófica. São Paulo: Nova Cultural, 1989.

GARO, I. L'enseignement de la philosophie en perspective. La Pensée, n.274, p.37-46, mars-avril 1990

GRISONI, D. Sartre: estrutura de la historia. In: Politicas de la filosofía. México: Fondo de Cultura Económica, 1982.

MARCUSE, H. The relevance of reality. In: BONTEMPO, C., ODELL, J. The owl of Minerva. New York: McGraw-Hill, 1975. p.231-44.

MERLEAU-PONTY, M. Em toda parte e em nenhuma. In: Sinais. Lisboa: Minotauro, 1962. p.189-237.

SARTRE, J.-P. Critique de la raison dialectique. Paris: Gallimard, 1960. 